\title{
A situational analysis of reported brain deaths in Malaysia from 2018-2019
}

\author{
Zaidani Attamimi
}

National Transplant Resource Center, Kuala Lumpur Hospital, Kuala Lumpur, Malaysia

Background: This study aims to describe barriers in diagnosing brain death by categorizing the data analyzed from the National Transplant Procurement Management Unit (NTPMU) registry.

Methods: Data records of the NTPMU registry from 2018-2019 were extracted. These data were analyzed to describe the following: (1) brain death proportion; (2) demographic characteristics; (3) admission and brain death test characteristics; (4) reason for brain death test not done; and (5) correlations.

Results: A total of 772 referrals were made, of which 322 were suspected for brain death. Out of this, 126 cases were confirmed for brain death, whereas 27 reported consent for organ donation. The proportion of confirmed brain deaths from the reported total deaths from $2018-2019$ is $16.5 \%$. Neurosurgical (57.5\%) and intensive care (78.1\%) units reported for the most referrals made. Severe traumatic brain injury (39.2\%) and spontaneous intracranial hemorrhage $(41.8 \%)$ are the two most frequent causes of admission with suspected brain death. Unable to correct parameters (34.7\%), cardiac death before test was done (31.2\%) and no clearance from family $(21.2 \%)$ are the most frequently reported causes for brain death test not done. Selected variables showed no correlation with duration between first and second brain death tests.

Conclusions: The barriers in diagnosing brain death are divided into clinical and non-clinical. A sound understanding in clinical knowledge and awareness among healthcare workers, a well-structured brain death consensus statement, properly executed training to improve attitudes and a well-managed awareness campaigns directing to the public are critical in overcoming these barriers.

Corresponding author: Zaidani Attamimi

E-mail: drzaidani@moh.gov.my

(c) The Korean Society for Transplantation

This is an Open Access article distributed under the terms of the Creative Commons Attribution Non-Commercial License (http://creativecommons.org/licenses/by-nc/4.0/) which permits unrestricted non-commercial use, distribution, and reproduction in any medium, provided the original work is properly cited. 